\title{
Cell-Type-Specific Regulation of Nucleus Accumbens Synaptic Plasticity and Cocaine Reward Sensitivity by the Circadian Protein, NPAS2
}

\author{
Puja K. Parekh, ${ }^{1 *}$ - Ryan W. Logan, ${ }^{1,2 *}$-Kyle D. Ketchesin, ${ }^{1}$ DDarius Becker-Krail, ${ }^{1}$ Micah A. Shelton, ${ }^{1}$ \\ ๑Mariah A. Hildebrand, ${ }^{1}$-Kelly Barko, ${ }^{1}$-Yanhua H. Huang, ${ }^{1}$ and ${ }^{\circledR C}$ Colleen A. McClung ${ }^{1,2}$ \\ ${ }^{1}$ Translational Neuroscience Program, Department of Psychiatry, University of Pittsburgh School of Medicine, Pittsburgh, Pennsylvania 15219, and ${ }^{2}$ Center \\ for Systems Genetics of Addiction, The Jackson Laboratory, Bar Harbor, Maine 04609
}

The circadian transcription factor neuronal PAS domain 2 (NPAS2) is linked to psychiatric disorders associated with altered reward sensitivity. The expression of Npas 2 is preferentially enriched in the mammalian forebrain, including the nucleus accumbens (NAc), a major neural substrate of motivated and reward behavior. Previously, we demonstrated that downregulation of NPAS2 in the NAc reduces the conditioned behavioral response to cocaine in mice. We also showed that Npas 2 is preferentially enriched in dopamine receptor 1 containing medium spiny neurons (D1R-MSNs) of the striatum. To extend these studies, we investigated the impact of NPAS2 disruption on accumbal excitatory synaptic transmission and strength, along with the behavioral sensitivity to cocaine reward in a cell-type-specific manner. Viral-mediated knockdown of Npas 2 in the NAc of male and female C57BL/6J mice increased the excitatory drive onto MSNs. Using Drdla-tdTomato mice in combination with viral knockdown, we determined these synaptic adaptations were specific to D1R-MSNs relative to non-D1R-MSNs. Interestingly, NAc-specific knockdown of Npas2 blocked cocaine-induced enhancement of synaptic strength and glutamatergic transmission specifically onto D1R-MSNs. Last, we designed, validated, and used a novel Cre-inducible short-hairpin RNA virus for MSN-subtype-specific knockdown of Npas2. Cell-type-specific Npas2 knockdown in D1RMSNs, but not D2R-MSNs, in the NAc reduced cocaine conditioned place preference. Together, our results demonstrate that NPAS2 regulates excitatory synapses of D1R-MSNs in the NAc and cocaine reward-related behavior.

Key words: circadian rhythms; cocaine; glutamatergic; nucleus accumbens; transcription factor

Significance Statement

Drug addiction is a widespread public health concern often comorbid with other psychiatric disorders. Disruptions of the circadian clock can predispose or exacerbate substance abuse in vulnerable individuals. We demonstrate a role for the core circadian protein, NPAS2, in mediating glutamatergic neurotransmission at medium spiny neurons (MSNs) in the nucleus accumbens (NAc), a region critical for reward processing. We find that NPAS2 negatively regulates functional excitatory synaptic plasticity in the NAc and is necessary for cocaine-induced plastic changes in MSNs expressing the dopamine 1 receptor (D1R). We further demonstrate disruption of NPAS2 in D1R-MSNs produces augmented cocaine preference. These findings highlight the significance of cell-type-specificity in mechanisms underlying reward regulation by NPAS2 and extend our knowledge of its function.

\section{Introduction}

Circadian rhythm disturbances are linked to the development and progression of neuropsychiatric illnesses, including sub-

\footnotetext{
Received Aug. 30, 2018; revised March 16, 2019; accepted April 3, 2019.

Author contributions: P.K.P., R.W.L., Y.H.H., and C.A.M. designed research; P.K.P., R.W.L., K.D.K., D.B.-K., M.A.S., M.A.H., K.B., and Y.H.H. performed research; P.K.P., R.W.L., K.D.K., D.B.-K., M.A.S., M.A.H., K.B., Y.H.H., and C.A.M. analyzed data; P.K.P., R.L., and C.A.M. wrote the paper.

This work was supported by the following funding sources: DA039865 (C.A.M.), DA041872 (C.A.M., R.W.L.), DA038654 (R.W.L.), and DA031111 (P.K.P.).

The authors declare no competing financial interests.

*P.K.P. and R.W.L. contributed equally to this work.
}

stance use disorders (Logan et al., 2014). Perturbations of the circadian system may contribute to the vulnerability for substance use (DePoy et al., 2017; Logan et al., 2018). Moreover, human genetic studies associate circadian gene variants and polymorphisms with mood and addiction disorders (McCarthy and Welsh, 2012; Shumay et al., 2012).

\footnotetext{
Correspondence should be addressed to Colleen A.McClung at mcclungca@upmc.edu. https://doi.org/10.1523/JNEUROSCI.2233-18.2019

Copyright $\odot 2019$ the authors
} 
Cellular and molecular rhythms are maintained by a series of transcriptional-translational feedback loops controlling tissue and cell-type-specific gene expression and functions (Koike et al., 2012; Partch et al., 2014). Rhythmic gene transcription is driven by the heterodimerization between brain and muscle Arnt-like protein-1 (BMAL1) and either circadian locomotor output cycles kaput (CLOCK) or the paralog, neuronal PAS domain protein 2 (NPAS2; Gekakis et al., 1998; Reick et al., 2001; Dioum et al., 2002). These bHLH-PAS domain circadian transcription factors share similar amino acid sequences and transcriptional action within the molecular clock (Hogenesch et al., 1997; Reick et al., 2001). When CLOCK is absent, NPAS2 is capable of compensating to maintain functional molecular rhythms in the brain and peripheral oscillators (DeBruyne et al., 2007; Landgraf et al., 2016). However, the expression of these transcription factors varies within the brain. Whereas CLOCK seems to be ubiquitously expressed, NPAS2 is enriched in the mammalian forebrain, particularly the nucleus accumbens (NAc; Garcia et al., 2000), a region that functions as a limbic-motor interface for processing salience and regulating mood and reward (Lobo and Nestler, 2011; Russo and Nestler, 2013). These patterns of expression may account for differential roles of these proteins in behavior. Indeed, NPAS2 is important for mice to adaptively entrain to restricted feeding schedules and for maintaining feeding conditions (Dudley et al., 2003; Wu et al., 2010). NPAS2-deficient mice also exhibit deficits in the acquisition of cued and contextual fear memory (Garcia et al., 2000). Previous studies from our lab have uncovered opposing roles of CLOCK and NPAS2 in mediating drug reward sensitivity. Clock mutant mice display an elevated behavioral response to cocaine measured by increased conditioned place preference (CPP), whereas NPAS2-deficient mice show decreased preference across similar doses (McClung et al., 2005; Ozburn et al., 2015). Furthermore, viral-mediated knockdown of Npas 2 exclusively within the accumbens reduces cocaine $\mathrm{CPP}$, further highlighting its importance in this limbic region (Ozburn et al., 2015). Interestingly, knockdown of Clock in the NAc has no effect on locomotor activity, exploratory drive, cocaine CPP, or glutamatergic transmission at NAc medium spiny neurons (MSNs; Ozburn et al., 2015; Parekh et al., 2018). These studies serve to underscore the relevance of region-specific differences in the functions of circadian proteins. They also highlight a unique role for accumbal Npas 2 in regulating rewardrelated behavior.

Drugs of abuse, like cocaine, increase mesolimbic dopaminergic signaling, which can remodel NAc excitatory synapses (Lüscher and Malenka, 2011). A majority of the NAc ( 95\%) is composed of GABAergic MSNs, which receive glutamatergic input from several regions, including the prefrontal cortex, amygdala, and ventral hippocampus, and dopaminergic input from the ventral tegmental area (Groenewegen et al., 1999; Bertran-Gonzalez et al., 2008; Smith et al., 2013). MSNs primarily express either dopamine 1 or 2 receptors (D1R or D2R; Lu et al., 1998; Bertran-Gonzalez et al., 2008). Their projection pathways further define these subpopulations with activation of D1RMSNs generally promoting goal-directed behavior, whereas activation of D2R-MSNs, generally inhibiting such behavior, although more recently functionality of these roles has been challenged (Smith et al., 2013; Kupchik et al., 2015). We previously demonstrated that Npas2 is enriched in D1R-MSNs of the striatum (Ozburn et al., 2015). Here, we further define how NPAS2 affects excitatory synaptic transmission in the NAc. We also demonstrate Npas2 disruption alters excitatory drive primarily onto D1R-MSNs, both in naive and cocaine exposed animals as well as the behavioral effect of cell-type-specific knockdown of Npas2 on cocaine reward sensitivity.

\section{Materials and Methods}

Animals. Male and female C57BL/6J (http://jaxmice.jax.org/strain/ 013636.html) and Drd1a-tdTomato (https://www.jax.org/strain/ 016204) mice (7-9 weeks) were used for viral-mediated gene knockdown and electrophysiological experiments. Adult (8-12 weeks) male Drdla:: Cre (http://jaxmice.jax.org/strain/024860) and Drd2::Cre mice maintained on the C57BL/6J background were used for cell-type-specific viral-mediated gene knockdown, cocaine administration $(20 \mathrm{mg} / \mathrm{kg}$, i.p., daily for $7 \mathrm{~d}$ ), and cocaine CPP experiments. Mice were maintained on a $12 \mathrm{~h}$ light/dark cycle (ZT0, lights on 7:00 A.M.; ZT12, lights off 7:00 P.M.). Food and water were available ad libitum. All animal use was conducted in accordance with the National Institute of Health guidelines for the care and use of laboratory animals and approved by the Institutional Animal Care and Use Committee of the University of Pittsburgh.

Viral-mediated gene transfer and stereotaxic surgery. Stereotaxic surgery was performed as previously described (Ozburn et al., 2017). Bilateral stereotaxic injections of $1 \mu \mathrm{l}$ of purified high titer adeno-associated virus (AAV2) containing shRNA for Npas2 or a scrambled sequence for controls tagged to GFP reporter were delivered into the NAc. Mice recovered for 3-4 weeks allowing for full viral expression before electrophysiological recording. A similar procedure was used to inject AAV2/ 2.H1lox.mCherry-Npas2-(or Scramble)-shRNA or AAV2-scramble virus for cocaine CPP experiments. Following behavioral testing, the placement of viral injections was verified histologically. Mice were perfused with ice-cold $1 \times$ PBS followed by $4 \%$ paraformaldehyde in PBS (PFA), $\mathrm{pH}$ 7.4. Brains were postfixed in PFA for $24 \mathrm{~h}$ then transferred to a $30 \%$ sucrose solution. Thirty-micrometer-thick tissue sections were used for visualizing localization of GFP, tdTomato, and mCherry signal. Sections were imaged at $4 \times$ magnification using an Olympus epifluorescence microscope.

Generation and validation of Cre-inducible shRNA and scramble viruses. AAV2/2.H1lox.mCherry-Npas2-shRNA virus was used for Creinducible shRNA expression for cell-type-specific knockdown of Npas2. These viruses were developed using a modified construct with an $\mathrm{H} 1$ pol.III promoter driving a loxP flanked STOP cassette and stuffer DNA preventing transcription of Npas 2 shRNA or a scrambled, nonfunctional sequence. The viral vector backbone was generously shared by Drs. Scott Russo, Icahn School of Medicine at Mount Sinai; and Michael Kaplitt, Weill Cornell Medicine. Recombination of the loxP elements in transgenic animals expressing Cre-recombinase allows for the removal of the stuffer DNA and the transcription of the shRNA sequence to achieve knockdown. The virus also contains a non-inducible mCherry reporter. The efficacy and specificity of the virus were validated using RNAscope Fluorescent Multiplex in situ hybridization (Advanced Cell Diagnostics). AAV2/2.H1lox.mCherry-Npas2-(or Scramble)-shRNA was injected into the NAc of Drd1a-Cre and Drd2-Cre mice, followed by 3 weeks of recovery to allow maximal viral expression.

Brains were sectioned via cryostat at $14 \mu \mathrm{m}$ and RNAscope in situ hybridization was then performed according to the manufacturer's instructions to determine colocalization between Cre and mCherry in the NAc (see Fig. 4C). Sections were imaged at $10 \times$ and $60 \times$ magnification using an Olympus FluoView FV1200 IX83 confocal microscope. Knockdown of Npas 2 by shRNA was confirmed from NAc tissue by quantitative real-time PCR. RNA extraction and cDNA synthesis were performed as described previously (Ozburn et al., 2015). Primers included: Npas2 (Forward, 5' GACACTGGAGTCCAGACGCAA and Reverse, 5e AATG TATACAGGGTGCGCCAAA) and $18 S$ (Forward, 5' ACCGCAGCTAG GAATAATGGA and Reverse, 5T GCCTCAGTTCCGAAAACCA). Reactions were run in duplicate in an Applied Biosystems 7900HT Fast Real-time PCR System (Applied Biosystems). Relative gene expression was calculated using the comparative $\mathrm{Ct}\left(2^{\Delta \Delta C t}\right)$ method and normalized to each sample's corresponding $18 \mathrm{~S}$ mRNA levels.

NAc slice preparation. Mice were anesthetized rapidly with isoflurane and decapitated. Brains were removed into ice-cold oxygenated (95\% $\mathrm{O}_{2} / 5 \% \mathrm{CO}_{2}$ ) modified artificial CSF (aCSF) containing the following (in $\mathrm{mM}$ ): $135 \mathrm{~N}$-methyl-D-glucamine, $1 \mathrm{KCl}, 1.2 \mathrm{KH}_{2} \mathrm{PO}_{4}, 1.5 \mathrm{MgCl}_{2}, 0.5$ 
A

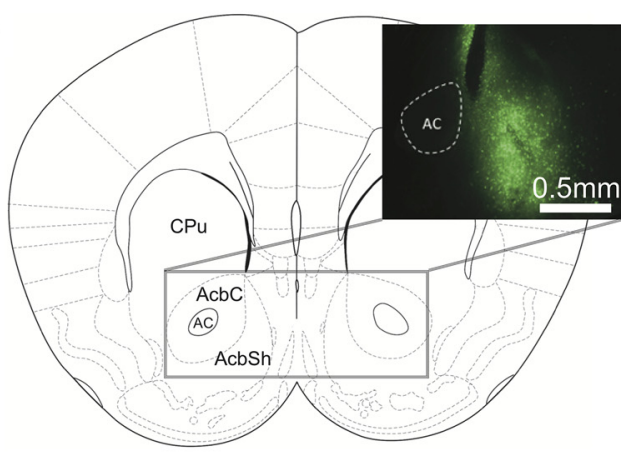

C

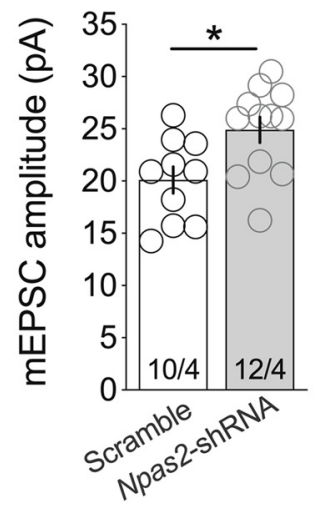

D

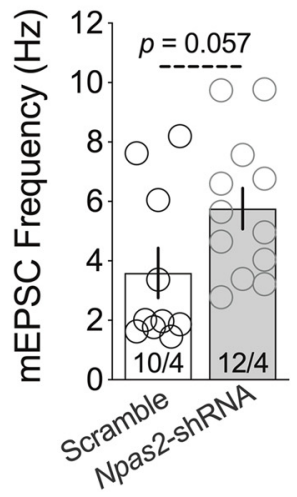

B

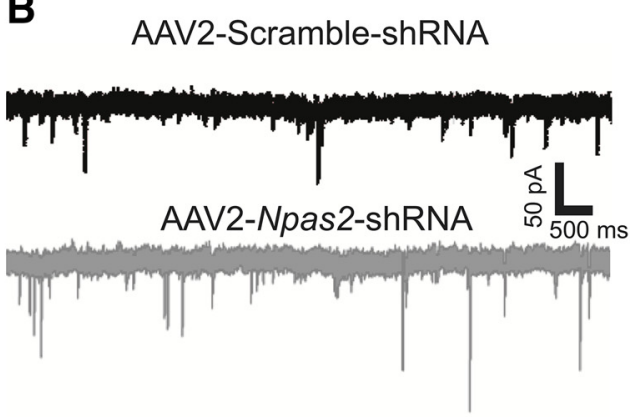

E

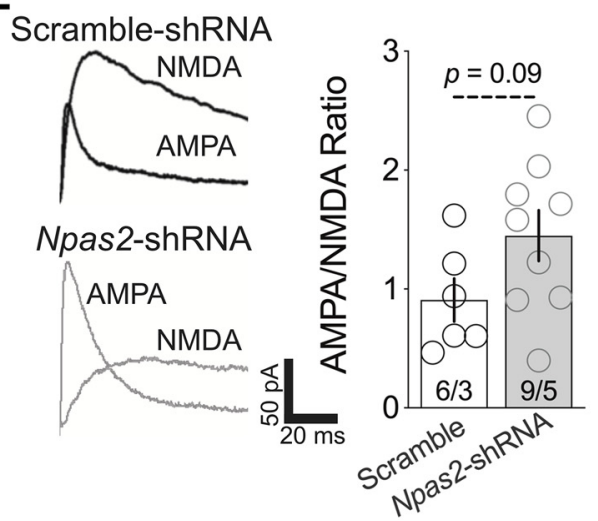

Figure 1. Knockdown of Npas2 in the NAc leads to an increase in excitatory transmission onto MSNs. $A$, Bilateral targeting of AAV2-Scramble-shRNA or AAV2-Npas2-shRNA to the NAc (left) and localization of GFP-tagged shRNA (inset). $\boldsymbol{B}$, Representative traces of mEPSCs sampled from scramble and Npas2-shRNA infected MSNs. $\boldsymbol{C}$, Summary of mEPSC amplitude in cells from both groups (white, Scramble; gray, Npas2-shRNA). D, Summary of mEPSC frequency. $\boldsymbol{E}$, Representative traces of AMPAR and NMDAR EPSCs from scramble and Npas2-knockdown MSNs (left). AMPA/NMDA ratio of evoked responses from both groups. $n=$ cells/animals. ${ }^{*} p<0.05$. AC, Anterior commissure; AcbC, accumbal core; AcbSh, accumbal shell; CPu, caudate putamen.

$\mathrm{CaCl}_{2}, 70$ choline bicarbonate, and 10 D-glucose, $\mathrm{pH} 7.4$ adjusted with $\mathrm{HCl}$. NAc-containing coronal slices $(200 \mu \mathrm{m})$ were sectioned with a vibratome (VT1200S; Leica) and incubated for $30 \mathrm{~min}$ at $37^{\circ} \mathrm{C}$ in oxygenated aCSF containing the following (in $\mathrm{mm}$ ): $119 \mathrm{NaCl}, 26 \mathrm{NaHCO}_{3}$, $2.5 \mathrm{KCl}, 1 \mathrm{NaH}_{2} \mathrm{PO}_{4}, 2.5 \mathrm{CaCl}_{2}, 1.3 \mathrm{MgCl}_{2}$, and $11 \mathrm{D}$-glucose. Slices were kept at room temperature until recording then perfused with aCSF $\left(30-32^{\circ} \mathrm{C}\right)$.

Whole-cell patch-clamp recordings. Recordings were conducted during the light phase. Slices were viewed by differential interference contrast optics (Leica) and accumbal regions were localized under lowmagnification. Recordings were made from NAc core and shell MSNs under visual guidance with a $40 \times$ objective. GFP and tdTomatoexpressing cells were visualized using filters for 488 and $546 \mathrm{~nm}$ light, respectively. Borosilicate glass pipettes (3-5 $\mathrm{M} \Omega$ ) were filled with the following (in mM): 117 Cs-MeSO 3 , 20 HEPES, 0.4 EGTA, $2.8 \mathrm{NaCl}, 5$ TEA-Cl, 2.5 Mg-ATP, 0.25 Na-GTP, and 5 QX-314, pH 7.3 adjusted with $\mathrm{CsOH}$. For miniature EPSC (mEPSC) intracellular solution contained the following (in mM): $119 \mathrm{~K}-\mathrm{MeSO}_{4}, 2 \mathrm{KCl}, 1 \mathrm{MgCl}_{2}, 1 \mathrm{EGTA}, 0.1 \mathrm{CaCl}_{2}$, 10 HEPES, $2 \mathrm{Mg}$-ATP, and 0.4 Na-GTP, pH 7.3 adjusted with KOH. Cells were voltage-clamped at $-70 \mathrm{mV}$. A constant-current isolated stimulator (DS3, Digitimer) was used to stimulate excitatory afferents with a monopolar electrode to record evoked currents (EPSCs). Picrotoxin (50 $\mu \mathrm{M}$; Sigma Aldrich) was included in the external perfusion aCSF to block gamma-aminobutyric acid receptors. TTX ( $1 \mu \mathrm{M}$; Tocris Bioscience) was used for mEPSC recordings to block action potential generation. For EPSC experiments, D-APV ( $50 \mu \mathrm{M}$; R\&D Systems) was bath applied to block NMDARs at $40 \mathrm{mV}$. In some experiments, D-APV was not applied and the peak amplitude of AMPAR current was measured at $-70 \mathrm{mV}$ and the NMDAR EPSC peak amplitude taken at $40 \mathrm{mV}, 35 \mathrm{~ms}$ from the AMPAR EPSC peak. Series resistance for all recordings was monitored continuously. Cells with a change in series resistance beyond $20 \%$ were excluded from data analysis, as were electrophysiologically identified interneurons. Synaptic currents were recorded with a MultiClamp 700A amplifier (Molecular Devices). Signals were filtered at $2.6-3 \mathrm{kHz}$ and amplified 10 times, then digitized at $20 \mathrm{kHz}$ with a Digidata $1322 \mathrm{~A}$ analog-to-digital converter (Molecular Devices). Miniature current recordings were analyzed using pClamp10 software (Molecular Devices) over a period of $\sim 2.5$ min during which $250-2500$ events were collected.

Cocaine conditioned reward. Cocaine CPP was assessed using a biased conditioning protocol during the light phase (ZT4-ZT6). On the pretest day, mice were allowed to freely explore the apparatus for $20 \mathrm{~min}$ to determine inherent bias. On conditioning Days 1 and 3, mice were injected with saline (i.p.) and paired with the preferred chamber of the apparatus, and on Days 2 and 4, received a cocaine injection $(5 \mathrm{mg} / \mathrm{kg}$, i.p.) paired with the non-preferred chamber. Conditioning sessions lasted $20 \mathrm{~min}$. Following conditioning, on Day 6, mice were tested again for time spent on either side of the apparatus and the CPP score was calculated by subtracting the preconditioning time spent in the cocainepaired side from the time spent in the cocaine-paired side on the test day.

Statistical analyses. Each experimenter was blind to genotype during electrophysiological and behavioral experiments. Significant differences were determined by Student's $t$ test or two-way ANOVA followed by Bonferroni or Tukey's post hoc tests. $p<0.05$ is considered significant for all analyses. All data are presented as mean \pm SEM.

\section{Results}

Knockdown of Npas 2 in the NAc leads to an increase in glutamatergic transmission at MSNs

We previously reported that knockdown of Npas2 in the NAc reduces cocaine CPP behavior (Ozburn et al., 2015). Changes in cocaine CPP have been correlated with alterations in excitatory neurotransmission at NAc MSNs, including the amplitude of mEPSCs and the ratio of evoked AMPAR- and NMDARmediated EPSCs (Grueter et al., 2013). Relative to control virus, we find Npas2-shRNA infected MSNs (Fig. 1A) exhibit signifi- 
cant increases in mEPSC amplitude $\left(t_{(20)}=2.71, p=0.01\right.$; unpaired $t$ test) and trending increases in frequency of events $\left(t_{(20)}\right.$ $=2.02, p=0.057$; unpaired $t$ test; Fig. $1 B-D)$. Additionally, the ratio of the average peak amplitude of AMPAR-mediated evoked currents to that of NMDAR EPSCs (AMPAR/NMDAR), a measure of synaptic strength independent of stimulus intensity or synapse number, trends toward an increase following Npas2 knockdown $\left(t_{(13)}=1.79, p=0.096\right.$; unpaired $t$ test; Fig. $\left.1 E\right)$. These results indicate that NPAS2 may negatively regulate MSN excitatory postsynaptic transmission, and potentially presynaptic release, mechanisms that may contribute to the modulation of reward sensitivity.

\section{Increased excitatory synaptic transmission following Npas2 knockdown is specific to D1 MSNs}

Given our previous findings showing preferential enrichment of Npas2 in striatal D1R-MSNs, we delivered scramble or Npas2shRNA AAVs into the NAc of Drd1a-tdTomato mice (Shuen et al., 2008), to identify D1R+ and non-D1R MSNs. Cells coexpressing tdTomato and GFP were considered virally infected $\mathrm{D} 1 \mathrm{R}+$ neurons, whereas those expressing only GFP were considered infected non-D1R neurons (Fig. 2A). Glutamatergic transmission was measured by analyzing the amplitude and frequency of AMPAR-mediated mEPSCs. Two-way ANOVA reveals a significant main effect of cell type on mEPSC amplitude $\left(F_{(1,43)}=\right.$ $5.39, p=0.025$ cell-type effect; $F_{(1,43)}=1.71, p=0.199$ treatment effect; $F_{(1,43)}=3.66, p=0.06$ interaction). Bonferroni's post hoc analyses confirm that mEPSC amplitude is significantly increased in D1R-MSNs following Npas2 knockdown compared with control $(p<0.05$; Fig. $2 B)$. Knockdown also increases the frequency of mEPSCs in a cell-type-specific manner $\left(F_{(1,43)}=4.234, p=\right.$ 0.046 cell type effect; $F_{(1,43)}=0.127, p=0.72$ treatment effect; $F_{(1,43)}=4.27, p=0.045$ interaction; ANOVA; Fig. $\left.2 D\right)$.

Consistent with the increase in AMPAR-mediated synaptic transmission, excitatory synaptic strength is exclusively increased in NPAS2-deficient D1R-MSNs as measured by AMPAR/ NMDAR ratio $\left(F_{(1,18)}=4.275, p=0.05\right.$ cell-type effect; $F_{(1,18)}=$ $10.34, p=0.005$ treatment effect; $F_{(1,18)}=10.76, p=0.004$ interaction; ANOVA; Fig. $2 F$ ). Together, our findings indicate a specific and robust regulation of glutamatergic signaling in the population of D1R-containing MSNs where NPAS2 is preferentially enriched.

\section{Npas 2 knockdown attenuates cocaine-induced potentiation of D1R-MSN excitatory synaptic strength and excitatory neurotransmission}

Studies have shown that cocaine remodels glutamatergic synaptic activity within the NAc (Kourrich et al., 2007; Schmidt and Pierce, 2010; Britt et al., 2012; Graziane et al., 2016). We therefore examined the cell-type-specific effects of repeated cocaine $(7 \mathrm{~d}$; cocaine $20 \mathrm{mg} / \mathrm{kg}$ i.p.) or saline administration on AMPAR/ NMDAR ratio following Npas2 knockdown (Fig. 3). Repeated cocaine administration reliably enhances the synaptic strength onto D1R-MSNs compared with saline administration in scramble-shRNA infected cells $\left(F_{(1,19)}=1.11, p=0.30\right.$ virus effect; $F_{(1,19)}=2.04, p=0.17$ treatment effect; $F_{(1,19)}=66.29$, $p<0.0001$ interaction; ANOVA followed by Tukey's multiplecomparisons tests, scramble-shRNA: saline vs cocaine, $p=$ 0.0006; Fig. 3A-C). Similar to naive conditions (Fig. $2 F$ ), knockdown of Npas2 increases the AMPAR/NMDAR ratio of D1R-MSNs in saline-treated animals (Scramble-shRNA vs Npas2-shRNA, $p=$ 0.0008; Fig. 3C). Furthermore, Npas2 knockdown prevents cocaine-induced potentiation of excitatory synaptic strength in
D1R-MSNs (Scramble-shRNA vs Npas2-shRNA, $p<0.0001$; Fig. $3 C)$. Npas 2 knockdown in non-D1R MSNs did not produce the same striking effects on cocaine-mediated adaptations of synaptic strength $\left(F_{(1,16)}=4.909, p=0.0416\right.$ virus effect; $F_{(1,16)}=$ 6.847, $p=0.02$ treatment effect; $F_{(1,16)}=0.13, p=0.72$ interaction; Fig. 3C).

We followed up these findings by recording mEPSCs to determine whether Npas2 disruption alters the effect of cocaine on AMPAR-mediated synaptic transmission (Fig. 4). Cocaine administration increased the amplitude of mEPSCs in D1R MSNs $\left(F_{(1,32)}=0.19, p=0.66\right.$ virus effect; $F_{(1,32)}=0.18, p=0.67$ treatment effect; $F_{(1,32)}=14.08, p=0.0007$ interaction, ANOVA followed by Tukey's multiple-comparisons tests, scrambleshRNA: saline vs cocaine, $p=0.03$; Fig. $4 C$ ). Furthermore, in accord with our previous result, Npas 2 knockdown significantly attenuated the cocaine-mediated increase in mEPSC amplitude in D1R MSNs (Scramble-ShRNA vs Npas2-shRNA, $p=0.03$; Fig. $4 C)$. Although in naive and saline-treated animals we had found that Npas2 knockdown increases synaptic transmission and strength, the effect on mEPSC amplitude in saline-treated animals here failed to reach significance (Scramble-ShRNA vs Npas2-shRNA, $p=0.17$ ). As anticipated, we found no significant effects of cocaine treatment or Npas2 knockdown on mEPSC amplitude in non-D1R MSNs $\left(F_{(1,35)}=0.017, p=0.9\right.$ virus effect; $F_{(1,35)}=0.229, p=0.64$ treatment effect; $F_{(1,35)}=0.0007$, $p=0.98$ interaction, ANOVA; Fig. $4 C$ ). Repeated cocaine administration and Npas2-shRNA both significantly increase the frequency of D1R MSN mEPSCs $\left(F_{(1,32)}=0.02, p=0.88\right.$ virus effect; $F_{(1,32)}=0.41, p=0.53$ treatment effect; $F_{(1,32)}=18.82$, $p=0.0001$ interaction, ANOVA followed by Tukey's multiplecomparisons tests, scramble-shRNA: saline vs cocaine, $p=0.005$; saline-treated: Scramble-shRNA vs Npas2-shRNA, $p=0.02$; Fig. $4 D)$. NPAS2-deficient D1R MSNs also fail to show an increase in mEPSC frequency in response to cocaine (Scramble-shRNA vs Npas2-shRNA, $p=0.02$; Fig. $4 D$ ). In the non-D1R cell population we find a significant main effect of treatment but nonsignificant effects of virus type or interaction $\left(F_{(1,35)}=3.32, p=0.08\right.$ virus effect; $F_{(1,35)}=5.17, p=0.03$ treatment effect; $F_{(1,35)}=$ 1.507, $p=0.23$ interaction, ANOVA; Fig. $4 D$ ). Together, these results suggest a strong cell-type-specific effect of NPAS2 on the ability of cocaine to remodel glutamatergic synapses in the NAc.

\section{D1R-MSN-specific Npas2 knockdown in the NAc reduces cocaine reward sensitivity}

Several cell-type-specific molecular mechanisms in the NAc that modulate cocaine reward behavior have been elucidated (Lobo et al., 2010, 2013; Grueter et al., 2013; Chandra et al., 2015, 2017a,b). Using Drd1a-Cre and Drd2-Cre mice, Cre-inducible mCherry tagged viruses were used to target D1R and D2Rexpressing cells in the NAc (Fig. 5A,C). RNAscope probes labeled Cre (white) and mCherry (orange) in Drd1a-Cre (Fig. 5C, top) and Drd2-Cre mice (Fig. 5C, bottom,). Following shRNAmediated knockdown, expression of Npas2 is significantly reduced in NAc homogenates of Drd1a-Cre mice $\left(t_{(19)}=4.428, p=\right.$ 0.0013 ) and trends toward significantly reduced in Drd2-Cre mice $\left(t_{(10)}=2.206, p=0.051\right.$; Fig. $\left.5 B\right)$.

Cell-type-specific knockdown in Cre mice was followed by cocaine CPP (Fig. 6A). Npas2 knockdown specifically within D1R-MSNs significantly reduces cocaine CPP compared with control animals $\left(t_{(20)}=2.451, p=0.024\right)$. No differences for cocaine CPP are observed after Npas2 knockdown in D2R-MSNs $(p=0.49)$. These findings are consistent with our previous findings demonstrating reduced cocaine preference in global 


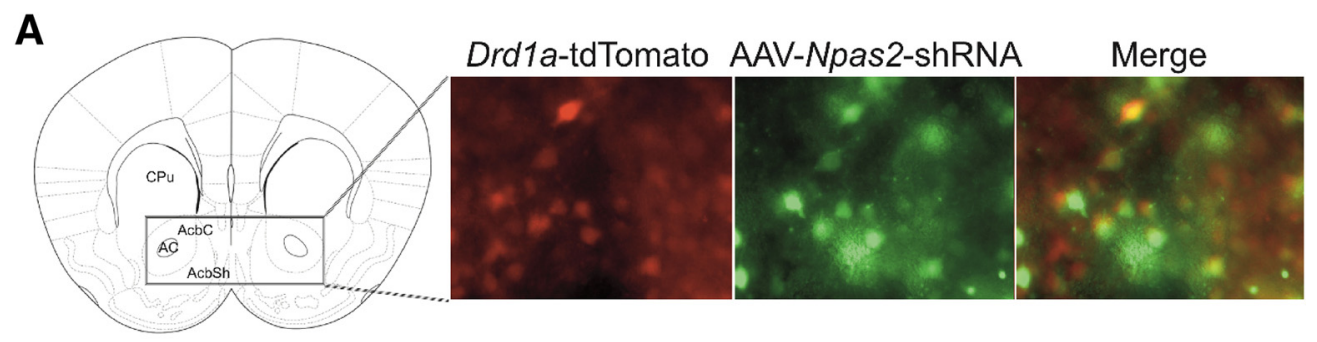

B

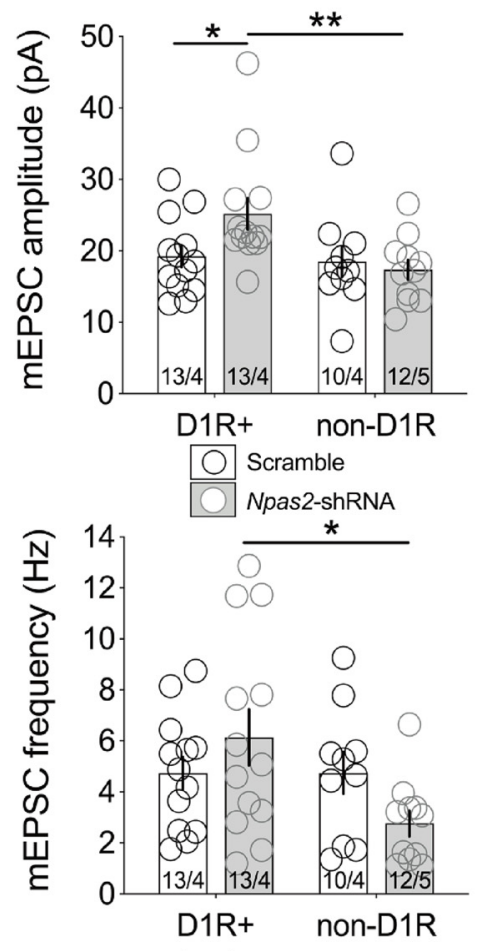

$\mathbf{F}$

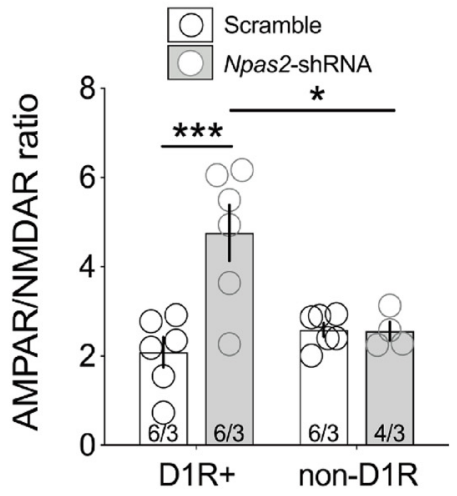

C

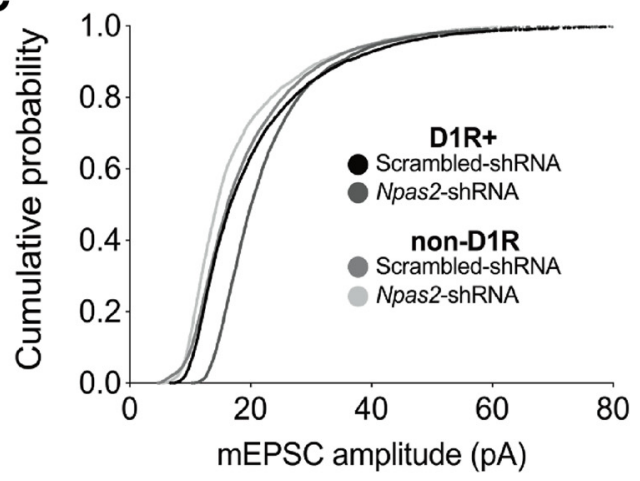

E

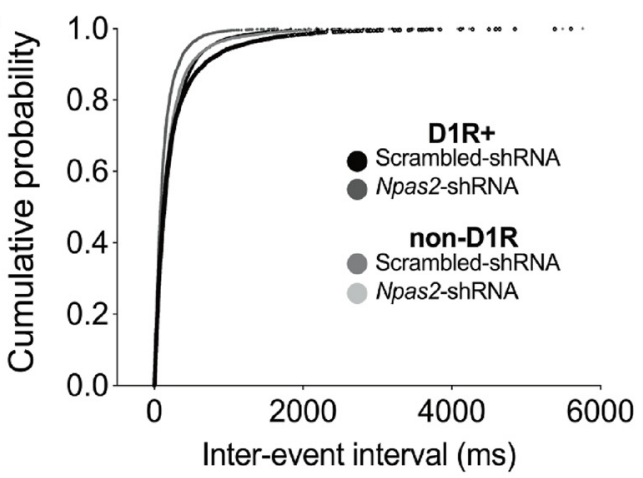

D1R-MSN

Scramble-shRNA

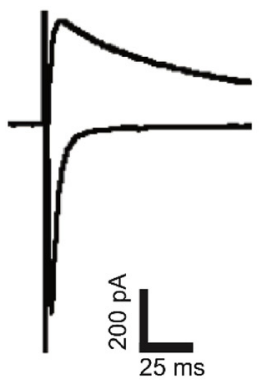

D1R-MSN

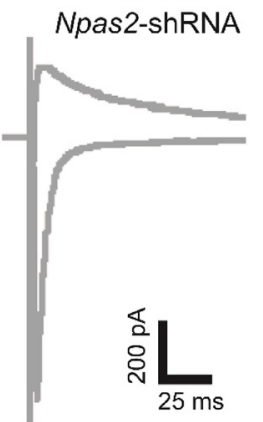

Figure 2. Increased excitatory synaptic transmission following Npas2-knockdown is specific to D1R-containing MSNs. A, Drd1a-tdTomato reporter mice were used to visualize D1R-MSNs and non-D1R MSNs in NAc slices from mice receiving either AAV2-Scramble-shRNA or AAV2-Npas2-shRNA. B, Summary of mEPSC amplitude in D1R and non-D1R neurons infected with Scramble or Npas2-shRNA virus. C, Cumulative probability of event amplitudes. $\boldsymbol{D}$, Frequency of miniature events in both groups and cell types. $\boldsymbol{E}$, Cumulative probability of $\mathrm{mEPSC}$ inter-event intervals. $\boldsymbol{F}$, Summary of AMPAR-NMDAR ratio of evoked currents. Representative traces of AMPAR $(-70 \mathrm{mV})$ and NMDAR $(40 \mathrm{mV})$ EPSCs from scramble or Npas2-shRNA viral infected D1R neurons. $n=$ cells/animals. ${ }^{*} p<0.05,{ }^{* *} p<0.01,{ }^{* * *} p<0.001$. AC, Anterior commissure; AcbC, accumbal core; AcbSh, accumbal shell; $\mathrm{CPu}$, caudate putamen.

NPAS2-deficient mice and preferential enrichment of Npas2 in D1R-MSNs (Ozburn et al., 2015), suggesting NPAS2 action in D1R-MSNs regulates cocaine reward sensitivity.

\section{Discussion}

Our study provides evidence for the cell-type-specific actions of the circadian transcription factor NPAS2, in the regulation of excitatory synaptic activity in the NAc, and cocaine-induced po- tentiation of synaptic strength and conditioned drug reward. Although circadian disruptions are linked to psychiatric disorders, including addiction, few studies have explored the potential functional role of molecular clocks and circadian transcription factors in brain reward regions and specific cell types. Previously, we found repeated non-contingent cocaine administration induced the expression of Npas2 specifically in the NAc (Falcon et al., 2013; Ozburn et al., 2015), and NAc-specific knockdown of 
Npas2 attenuated the development of cocaine CPP (Ozburn et al., 2015). Here, NAc-specific knockdown of Npas2 led to an overall increase in mEPSC amplitude, usually indicative of either higher density or conductance of postsynaptic AMPA receptors at individual excitatory synapses. In support of this, we observed a trending increase in the AMPAR/NMDAR ratio in MSNs with reduced NPAS2. A trend-level increase in the frequency of miniature currents at MSNs was also observed, which with these other changes of synaptic activity following Npas 2 knockdown, implies elevated presynaptic release probability of glutamate at the synapse or an increase in the number of functional synaptic sites through an unknown mechanism. These increases were weaker with reduced NPAS2, possibly due to indiscriminate sampling of specific MSN subtypes. Indeed, our additional studies define NPAS2 as a critical modulator of synaptic activity selectively at D1R-MSNs in the NAc. Interestingly, we have also previously found that Npas 2 knockdown in the NAc alters inhibitory synaptic activity at MSNs, decreasing the amplitude of mIPSCs and expression of the GABA $\mathrm{A}$ receptor subunit gene, Gabral (Ozburn et al., 2017). Together with our current results, this suggests that NPAS2 may play a critical role in maintaining balance of excitatory and inhibitory input in this region. We have not yet investigated whether this effect on GABAergic neurotransmission is restricted to a particular subtype of MSN.

We previously used Drd1a-tdTomato mice to isolate D1R-MSNs from the mouse striatum using FACs analysis. Relative to non-DR1-MSNs, which are presumably D2R-MSNs, there was an $\sim 80$-fold enrichment of Npas2 in D1R-MSNs (Ozburn et al., 2015). Using a similar approach combined with viral-mediated knockdown, we found Npas2 knockdown in D1R-MSNs increased AMPAR mEPSC amplitudes and frequencies relative to control virus and non-D1R-MSNs. Moreover, AMPAR/NMDAR ratios were significantly elevated, an effect specific to D1R-MSNs. These results suggest NPAS2 influences excitatory synaptic transmission through adaptations selectively in D1R-MSNs.

Many studies support the primary role of D1R-MSNs in the NAc to promote the rewarding effects of cocaine (Lobo et al., 2010; Lobo and Nestler, 2011; Chandra et al., 2013, 2015, 2017a,b; Smith et al., 2013; Koo et al., 2014). Furthermore, many of the molecular and synaptic plasticity changes following cocaine administration, regardless of contingency, occur in D1RMSNs. For example, non-contingent experimenter administered acute or repeated cocaine administration increases AMPAR/ NMDAR ratios and the frequency of mEPSCs in D1R-MSNs (Dobi et al., 2011). In the present study, we found shRNAmediated knockdown of Npas2 led to similarly potentiated excitatory synapses at D1R-MSNs. These findings together with our previous results (Falcon et al., 2013; Ozburn et al., 2015), suggest

\section{B Cocaine}
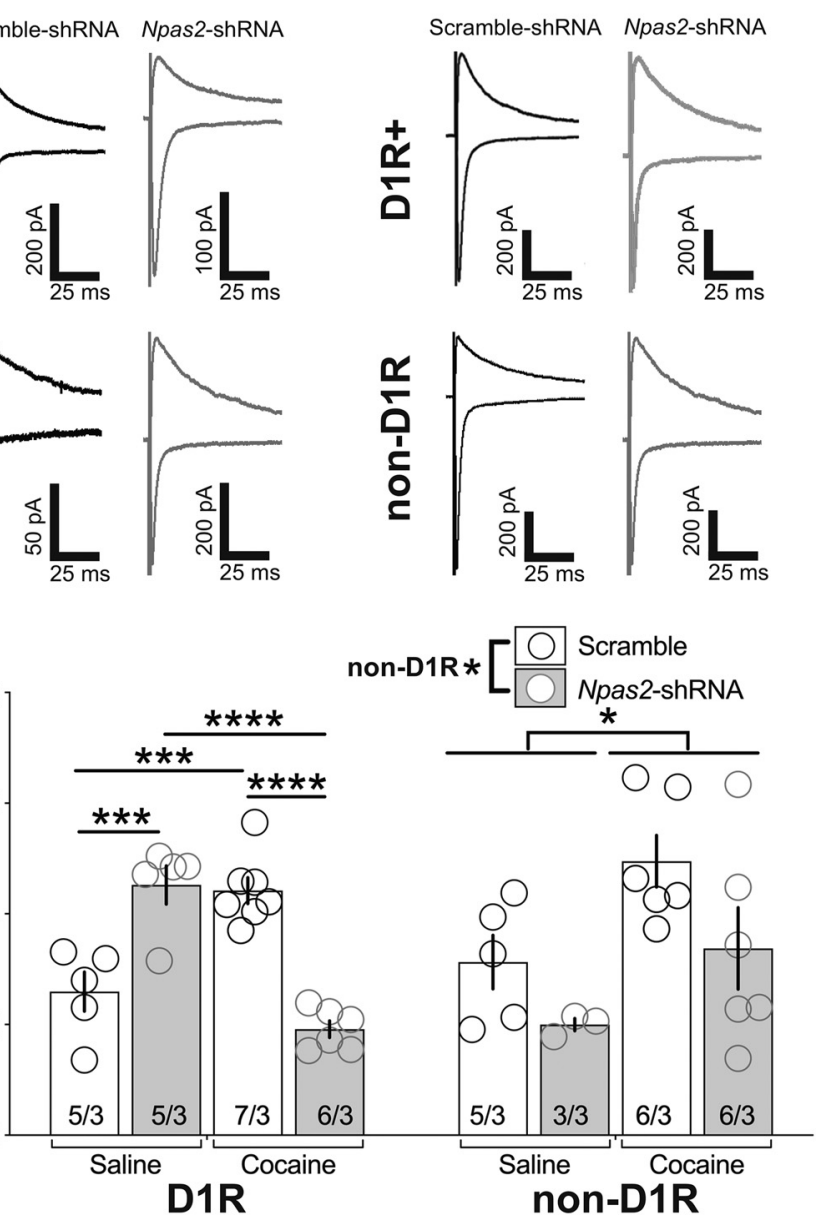

Figure 3. Knockdown of Npas2 inhibits cocaine-induced potentiation of D1R-MSN excitatory synaptic strength. Representative traces of AMPAR( $-70 \mathrm{mV}$ ) and NMDAR (40 mV) EPSCs from D1R-MSNs and non-D1R-MSNs infected with scramble or Npas2shRNA virus from mice receiving $(\boldsymbol{A})$ saline or $(\boldsymbol{B}) 20 \mathrm{mg} / \mathrm{kg}$ cocaine (i.p.) for $7 \mathrm{~d}$. C, Summary of AMPAR/NMDAR ratio of evoked currents. $n=$ cells/animals. ${ }^{*} p<0.05,{ }^{* * *} p<0.001,{ }^{* * * *} p<0.0001$.

cocaine alters the expression and function of NPAS2 in the NAc, leading to an overall change in synaptic homeostasis. These findings implicate NPAS2 as a key transcriptional modulator of cocaine-induced synaptic plasticity.

In the NAc, NPAS2 may transcriptionally regulate several key pathways involved in excitatory synaptic homeostasis and plasticity (Ozburn et al., 2015). Our previous findings from NPAS2 ChIP-seq in mouse NAc revealed several strong candidates related to synaptic structure and function, and cocaine reward, including brain derived neurotrophic factor (Bdnf; Graham et al., 2007; Schoenbaum et al., 2007; Heiman et al., 2008; Anderson et al., 2017; Bobadilla et al., 2018), Rho-associated coiled-coilcontaining protein kinase 1 (Rock1; Nakagawa et al., 1996; Henderson et al., 2016), and others which we have recently confirmed, including GABA receptor $\alpha 1$ (Gabra1; Ozburn et al., 2017). Other intriguing candidates previously linked to cocaine include multiple genes in the nuclear factor $\kappa$-B signaling pathways (Russo et al., 2009). Interestingly, investigating the overlap among potential NPAS2 targets and genes altered in D1R-MSN and D2R-MSN by cocaine administration (Heiman et al., 2008) reveals several candidates relevant to cocaine and synaptic signaling, such as glutamate decarboxylase 1 (Gad1; Enoch et al., 2012; Levran et al., 2016), glutamate ionotropic receptor AMPA 1 and 2 
A

\section{Saline}

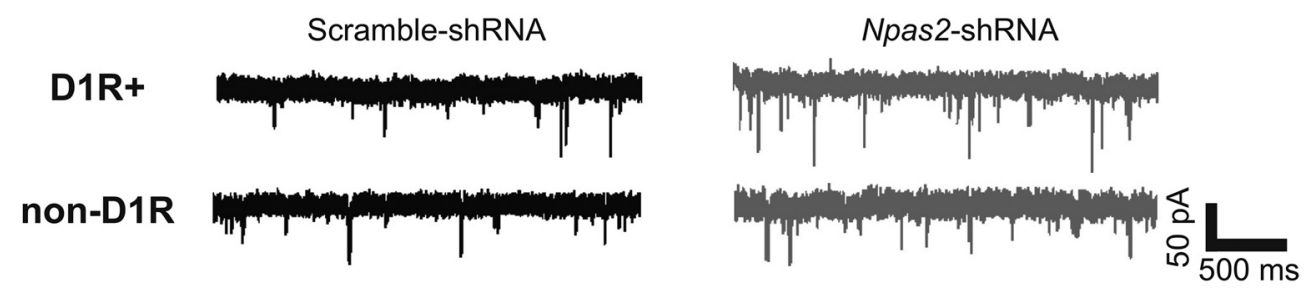

B

Cocaine

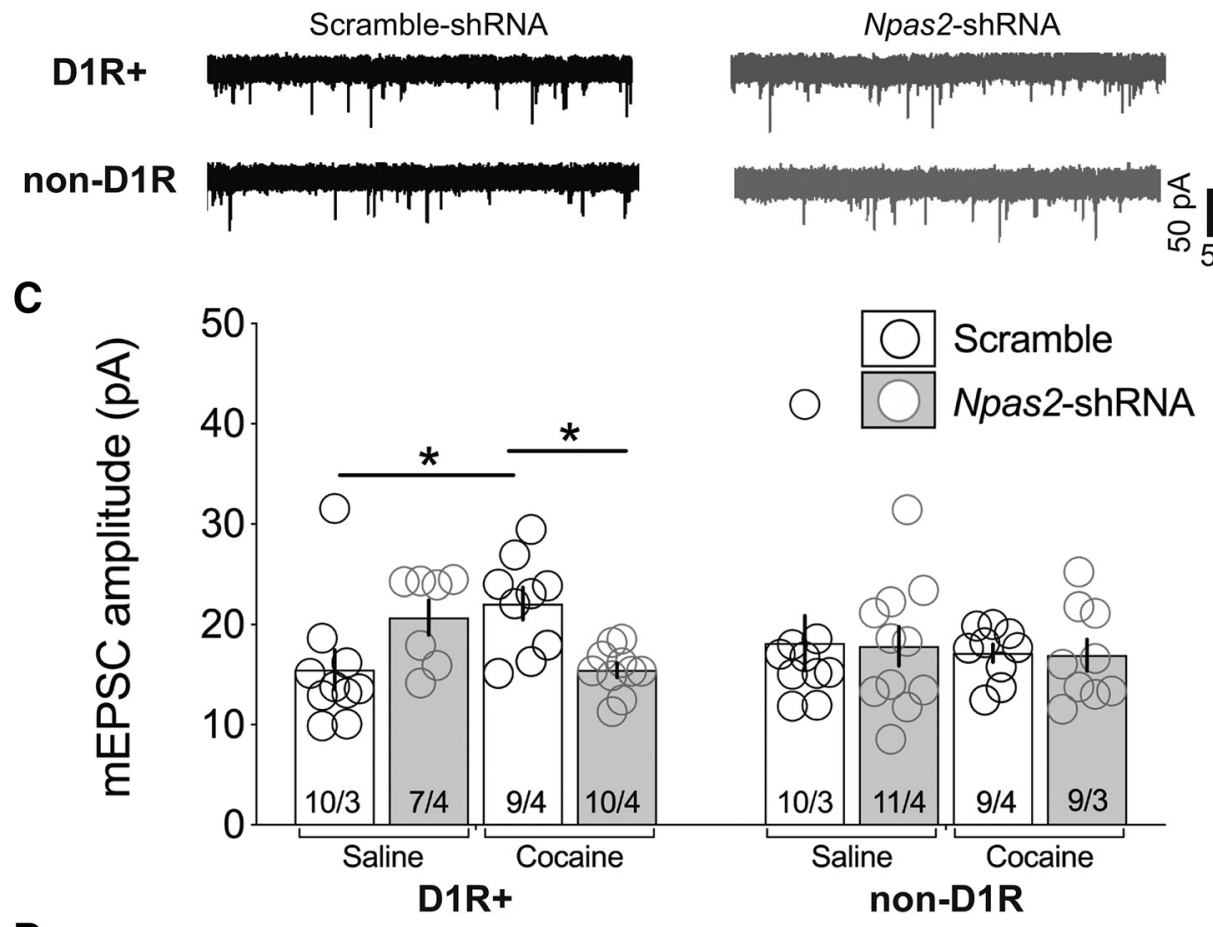

D

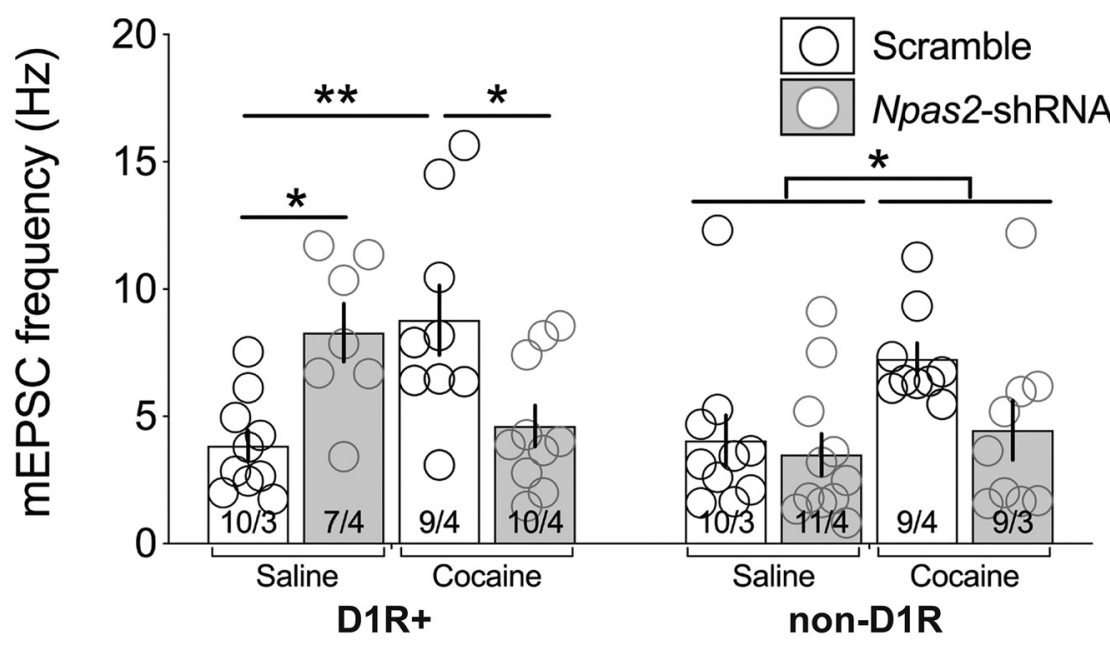

Figure 4. Knockdown of Npas2 attenuates cocaine-induced potentiation of D1R-MSN excitatory transmission. Representative traces of AMPAR-mediated mEPSCS ( $-70 \mathrm{mV}$ ) from D1R- and non-D1R MSNs infected with scramble or Npas2-shRNA from mice receiving $(\boldsymbol{A})$ saline or $(\boldsymbol{B}) 20 \mathrm{mg} / \mathrm{kg}$ cocaine (i.p.) for $7 \mathrm{~d}$. C, Summary of mEPSC amplitude. $\boldsymbol{D}$, Summary of mEPSC frequency. $n=$ cells/animals. ${ }^{*} p<0.05,{ }^{* *} p<0.01$.

(Gria1,2; Mead et al., 2005; Briand et al., 2016), glutamate ionotropic receptor NMDA 2a,b (Grin2a,b; Eipper-Mains et al., 2013), early growth response 1 (Egr1; Thiriet et al., 2000; Xu and Kang, 2014; Duclot and Kabbaj, 2017; Muñiz et al., 2017), nuclear receptor corepressor 1 (Ncor1; Gelernter et al., 2014), period 3
(Per3; Falcon et al., 2013), SIN3 transcription regulator B (Sin3b; Chandrasekar and Dreyer, 2010), and $\beta$-secretase 1 (Bace1; Miyazaki et al., 2007; Bu et al., 2012). Future studies will explore whether NPAS2 directly regulates the transcription of these genes and their role in cocaine-induced synaptic and behavioral plasticity. 
A

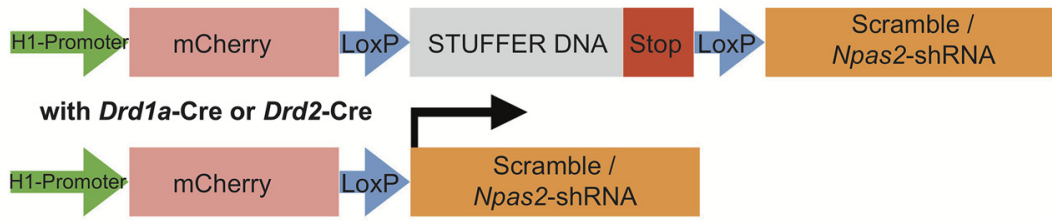

B

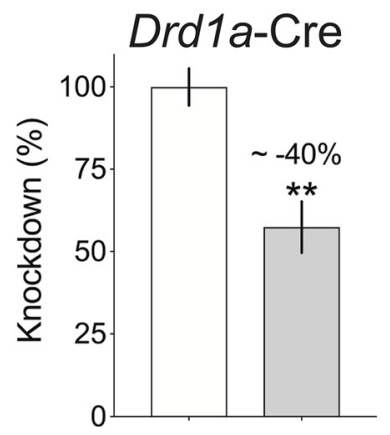

C
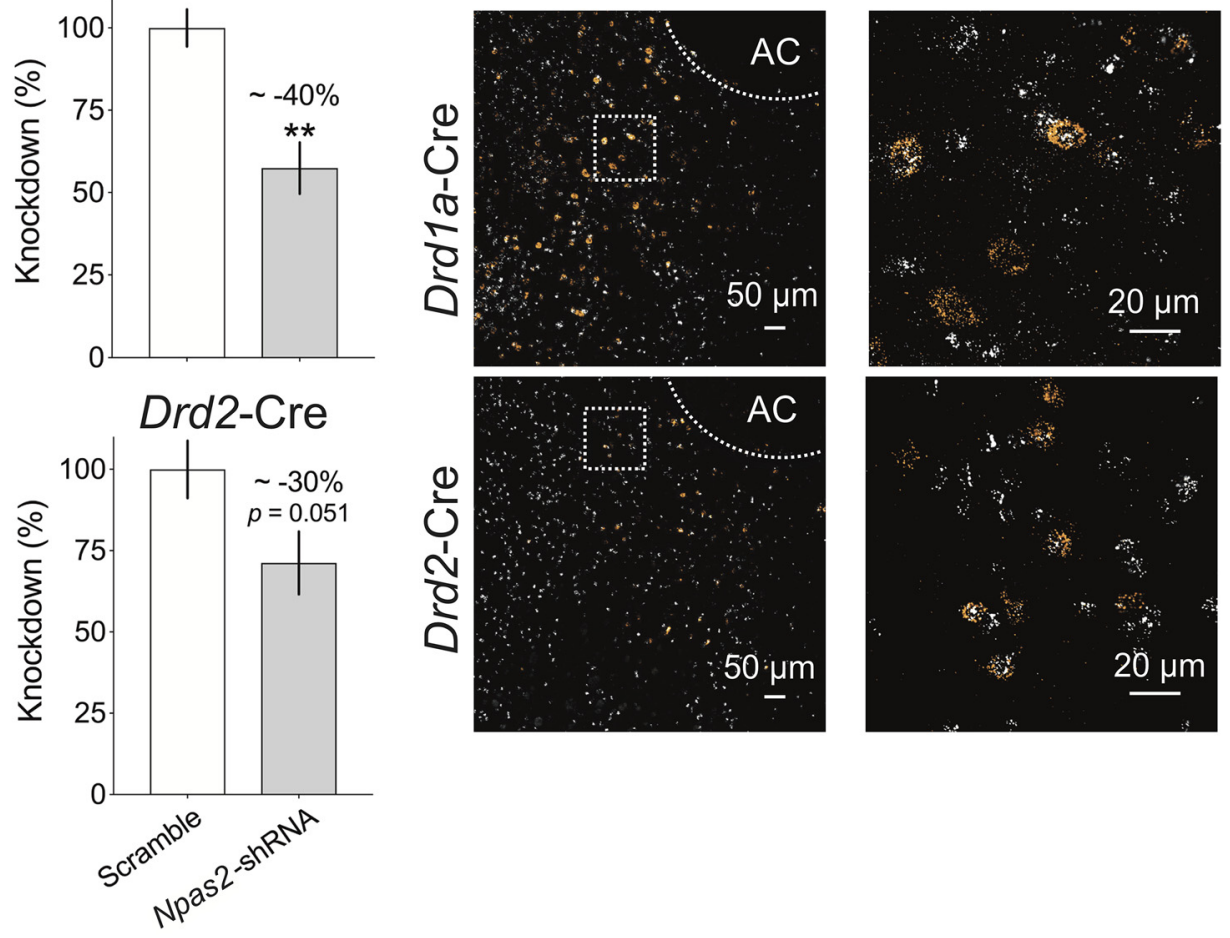

Figure 5. Validation of a novel viral construct to selectively knock down Npas2 in NAc MSNs. A, Stuffer DNA is removed upon recombination of loxP elements in Cre-expressing animals followed by the activation of Scramble or Npas2-shRNA construct. B, Expression of Cre-inducible Npas2-shRNA in the NAc (regional homogenates) of Drd1a-Cre mice leads to a significant reduction in the relative mRNA expression of Npas2 compared with scramble virus. C, Representative RNAscope in situ hybridization micrographs (white, (re; orange, mCherry) of the NAc from Drd 1a-Cre (top) and Drd2-Cre (bottom) mice following 3 weeks of AAV2-H1.lox.mCherry-Npas2-shRNA. Area in the box is enlarged to depict cells expressing Cre and mCherry. AC, Anterior commissure. $n=6$ animals per group. ${ }^{* *} p<0.01$.

Potentiation of excitatory synapses at D1R-MSNs in the NAc occurs in response to a variety of cocaine administration paradigms (Borgland et al., 2004; Dobi et al., 2011; Lewitus et al., 2016). We report knockdown of Npas2 in the NAc completely blocked cocaine-induced increases of AMPAR/NMDAR ratios and amplitude and frequency of mEPSCs in D1R-MSNs, which supports NPAS2 as a major modulator of cocaine-induced plasticity in specific cell types of the NAc. Enhanced excitatory synapses at D1R-MSNs may be mediated by dopamine action at these receptors (Conrad et al., 2008; Moussawi et al., 2009; Lobo et al., 2010), as cocaine-induced dopamine D1R activation promotes AMPAR trafficking and insertion of GluA1-containing AMPARs (Conrad et al., 2008; Moussawi et al., 2009). These are strengthened by repeated cocaine administration, further increasing the cell surface expression of AMPARs and AMPAR/ NMDAR ratios, which are important for several cocaine rewardrelated behaviors (Pierce et al., 1996; Chao et al., 2002; Suto et al., 2004; Boudreau and Wolf, 2005; Conrad et al., 2008; Moussawi et al., 2009). Interestingly, activation of D1Rs, but not D2Rs, on primary striatal neurons in vitro increased the expression of Npas2 (Imbesi et al., 2009), potentially acting as a transcriptional driver of cocaine-induced molecular changes and synaptic plasticity in specific striatal cell types.

We used a cell-type-specific viral-mediated approach to investigate whether knocking down NPAS2 specifically in D1R-MSNs or D2R-MSNs impacts cocaine reward behavior. Overall, activation of D1R-MSNs promotes cocaine conditioned reward, whereas activation of D2R-MSNs attenuates reward (Kourrich et al., 2007; Bertran-Gonzalez et al., 2008; Lobo et al., 2010; Chandra et al., 2013; Grueter et al., 2013). Given NAc-specific knockdown of Npas2 attenuated cocaine CPP and our previous expression findings indicated preferential expression of Npas 2 in D1R-MSNs (Ozburn et al., 2015) together with our electrophysiology results, we predicted D1R-MSN-specific Npas2 knockdown would reduce cocaine CPP behavior. Indeed, celltype-specific knockdown of Npas2 in D1R-MSNs significantly reduced cocaine conditioned reward at the same dose $(5 \mathrm{mg} /$ $\mathrm{kg}$ ) that produced differences in reward in global NPAS2deficient mice (Ozburn et al., 2015). There was no effect of Npas2 knockdown in D2R-MSNs on cocaine CPP. Together, these results begin to reveal the cell-type-specific impact of NPAS2 on cocaine reward behavior. 


\section{A Stereotaxic Delivery (NAc)}

AAV2-H1.lox.mCherry-Scramble-shRNA

AAV2-H1.lox.mCherry-Npas2-shRNA

Adult male mice

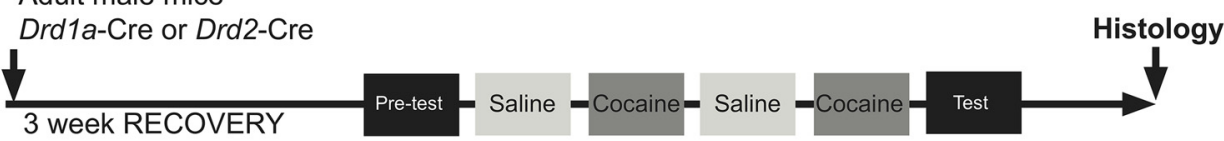

B
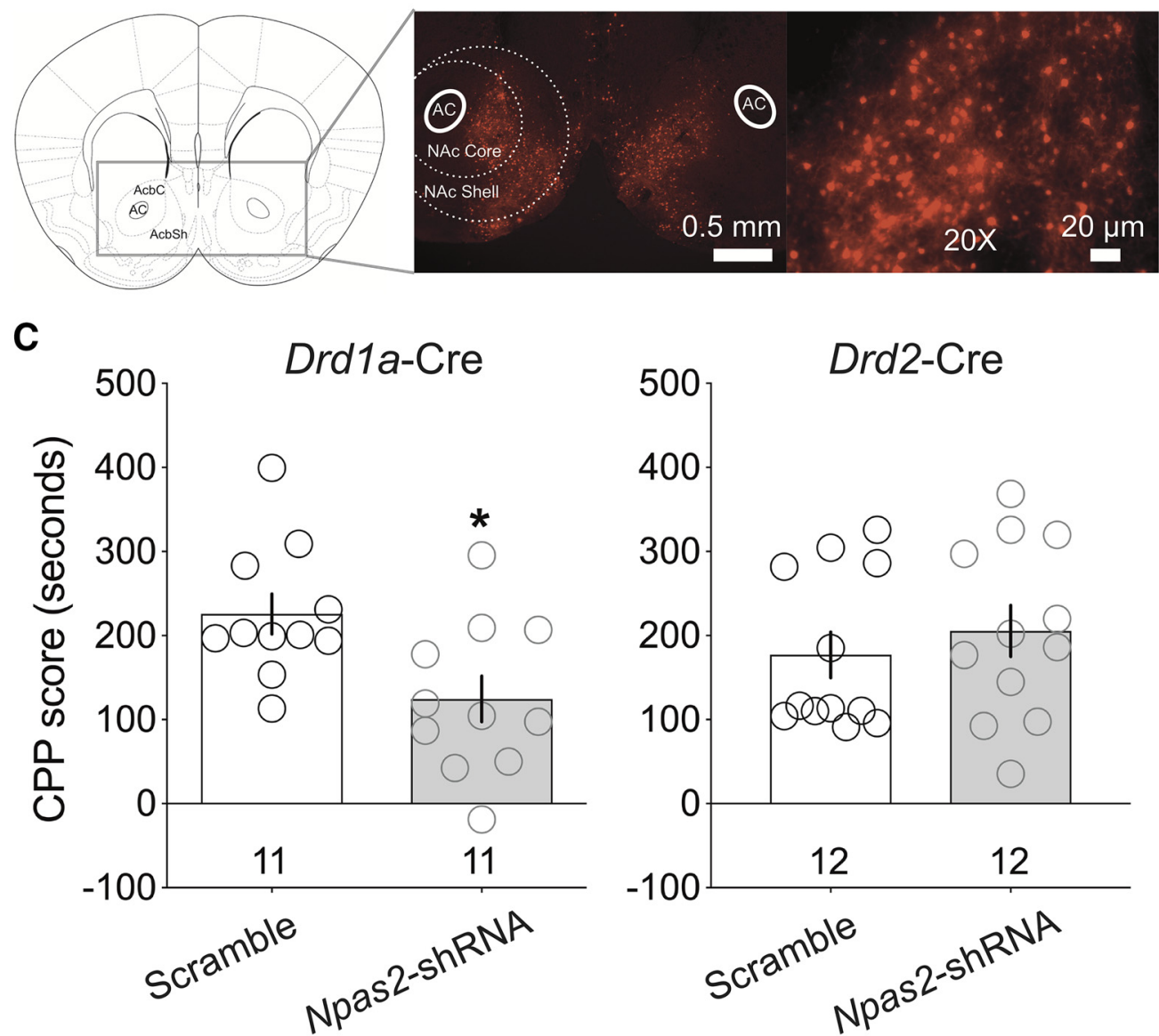

Figure 6. Viral-mediated knockdown of Npas2 specifically in D1R-MSNs reduces cocaine CPP. $\boldsymbol{A}$, Timeline of stereotaxic viral injections, conditioning paradigm and histological verification. $\boldsymbol{B}$, Representative micrograph of mCherry expression indicating presence and location of (re-inducible shRNA virus within the NAc (left) and 20× image of virus expression within NAc cells (right). $C$, CPP score (test-pretest duration) for scramble and Npas2-shRNA-treated Drd1a-Cre and Drd2-Cre mice. AC, Anterior commissure; AcbC, accumbal core; AcbSh, accumbal shell. $n=$ animals. ${ }^{*} p<0.05$.

Studies have shown D1R-MSNs are recruited during repeated cocaine administration, and during and following cocaine CPP (Calipari et al., 2016). Thus, the effects of cocaine on MSN subtypes depend on the context, dose, and frequency of administration. Activation of D1Rs by cocaine-induced dopamine transmission may activate NPAS2-mediated signaling pathways involved in AMPAR trafficking, receptor expression, or other processes involved in synaptic plasticity. Interestingly, knockdown of Npas2 leads to a modest decrease in the AMPA-NMDA ratio of non-D1R-MSNs following either saline or cocaine administration, which was not found in naive animals, suggesting compensatory interactions between D1R-MSNs and potentially D2R-MSNs. In addition, higher resolution, finer mapping of NPAS2 expression and activity could reveal more subtle activitydependent changes varying across NAc subregions and cell types.

Our findings continue to support the mechanistic links be- tween clocks and reward and their direct action in the regulation of reward behavior. Mice with a mutation in Clock, which is a functional homolog of NPAS2, have increased cocaine preference and self-administration, linked to increased cell firing and bursting activity of ventral tegmental area (VTA) dopamine neurons (McClung et al., 2005; Coque et al., 2011; Ozburn et al., 2012; Spencer et al., 2012). Similarly, knockdown of Clock specifically in the VTA also leads to increased dopaminergic neurotransmission (McClung et al., 2005; Mukherjee et al., 2010). Importantly, CLOCK knockdown in the NAc had no effect on cocaine CPP (Ozburn et al., 2015). Therefore, despite their homology in structure and function, CLOCK and NPAS2, appear to differentially modulate cellular physiology depending on brain region and cell type, and behaviors related to reward.

Collectively, our studies reveal a novel role for NPAS2 in NAc MSNs to regulate cocaine-induced synaptic and reward-related 
behavior. We show NPAS2 in the NAc modulates the strength and sensitivity of excitatory synapses preferentially in D1RMSNs. We also demonstrate NPAS2 specifically in D1R-MSNs is critical for the normal expression of cocaine conditioned place preference. Our data provides further understanding of the cellular and molecular mechanisms underlying the relationships between circadian rhythms, reward circuits. and drug-related behaviors.

\section{References}

Anderson EM, Wissman AM, Chemplanikal J, Buzin N, Guzman D, Larson EB, Neve RL, Nestler EJ, Cowan CW, Self DW (2017) BDNF-TrkB controls cocaine-induced dendritic spines in rodent nucleus accumbens dissociated from increases in addictive behaviors. Proc Natl Acad Sci U S A 114:9469-9474.

Bertran-Gonzalez J, Bosch C, Maroteaux M, Matamales M, Hervé D, Valjent E, Girault JA (2008) Opposing patterns of signaling activation in dopamine D1 and D2 receptor-expressing striatal neurons in response to cocaine and haloperidol. J Neurosci 28:5671-5685.

Bobadilla AC, Garcia-Keller C, Chareunsouk V, Hyde J, Camacho DM, Heinsbroek JA, Kalivas PW (2018) Accumbens brain-derived neurotrophic factor (BDNF) transmission inhibits cocaine seeking. Addict Biol. Advance online publication. Retrieved June 11, 2018. doi:10.1111/ adb. 12638.

Borgland SL, Malenka RC, Bonci A (2004) Acute and chronic cocaineinduced potentiation of synaptic strength in the ventral tegmental area: electrophysiological and behavioral correlates in individual rats. J Neurosci 24:7482-7490.

Boudreau AC, Wolf ME (2005) Behavioral sensitization to cocaine is associated with increased AMPA receptor surface expression in the nucleus accumbens. J Neurosci 25:9144-9151.

Briand LA, Deutschmann AU, Ellis AS, Fosnocht AQ (2016) Disrupting GluA2 phosphorylation potentiates reinstatement of cocaine seeking. Neuropharmacology 111:231-241.

Britt JP, Benaliouad F, McDevitt RA, Stuber GD, Wise RA, Bonci A (2012) Synaptic and behavioral profile of multiple glutamatergic inputs to the nucleus accumbens. Neuron 76:790-803.

Bu Q, Hu Z, Chen F, Zhu R, Deng Y, Shao X, Li Y, Zhao J, Li H, Zhang B, Lv L, Yan G, Zhao Y, Cen X (2012) Transcriptome analysis of long noncoding RNAs of the nucleus accumbens in cocaine-conditioned mice. J Neurochem 123:790-799.

Calipari ES, Bagot RC, Purushothaman I, Davidson TJ, Yorgason JT, Peña CJ, Walker DM, Pirpinias ST, Guise KG, Ramakrishnan C, Deisseroth K, Nestler EJ (2016) In vivo imaging identifies temporal signature of D1 and D2 medium spiny neurons in cocaine reward. Proc Natl Acad Sci U S A 113:2726-2731.

Chandra R, Lenz JD, Gancarz AM, Chaudhury D, Schroeder GL, Han MH, Cheer JF, Dietz DM, Lobo MK (2013) Optogenetic inhibition of D1R containing nucleus accumbens neurons alters cocaine-mediated regulation of Tiam1. Front Mol Neurosci 6:13.

Chandra R, Francis TC, Konkalmatt P, Amgalan A, Gancarz AM, Dietz DM, Lobo MK (2015) Opposing role for Egr3 in nucleus accumbens cell subtypes in cocaine action. J Neurosci 35:7927-7937.

Chandra R, Engeln M, Francis TC, Konkalmatt P, Patel D, Lobo MK (2017a) A role for peroxisome proliferator-activated receptor gamma coactivatorlalpha in nucleus accumbens neuron subtypes in cocaine action. Biol Psychiatry 81:564-572.

Chandra R, Engeln M, Schiefer C, Patton MH, Martin JA, Werner CT, Riggs LM, Francis TC, McGlincy M, Evans B, Nam H, Das S, Girven K, Konkalmatt P, Gancarz AM, Golden SA, Iñiguez SD, Russo SJ, Turecki G, Mathur BN, et al. (2017b) Drpl mitochondrial fission in D1 neurons mediates behavioral and cellular plasticity during early cocaine abstinence. Neuron 96:1327-1341 e1326.

Chandrasekar V, Dreyer JL (2010) The brain-specific neural zinc finger transcription factor $2 \mathrm{~b}$ (NZF-2b/7ZFMyt1) suppresses cocaine selfadministration in rats. Front Behav Neurosci 4:14.

Chao SZ, Ariano MA, Peterson DA, Wolf ME (2002) D1 dopamine receptor stimulation increases GluRl surface expression in nucleus accumbens neurons. J Neurochem 83:704-712.

Conrad KL, Tseng KY, Uejima JL, Reimers JM, Heng LJ, Shaham Y, Marinelli
M, Wolf ME (2008) Formation of accumbens GluR2-lacking AMPA receptors mediates incubation of cocaine craving. Nature 454:118-121.

Coque L, Mukherjee S, Cao JL, Spencer S, Marvin M, Falcon E, Sidor MM, Birnbaum SG, Graham A, Neve RL, Gordon E, Ozburn AR, Goldberg MS, Han MH, Cooper DC, McClung CA (2011) Specific role of VTA dopamine neuronal firing rates and morphology in the reversal of anxietyrelated, but not depression-related behavior in the ClockDelta19 mouse model of mania. Neuropsychopharmacology 36:1478-1488.

DeBruyne JP, Weaver DR, Reppert SM (2007) CLOCK and NPAS2 have overlapping roles in the suprachiasmatic circadian clock. Nat Neurosci 10:543-545.

DePoy LM, McClung CA, Logan RW (2017) Neural mechanisms of circadian regulation of natural and drug reward. Neural Plast 2017:5720842.

Dioum EM, Rutter J, Tuckerman JR, Gonzalez G, Gilles-Gonzalez MA, McKnight SL (2002) NPAS2: a gas-responsive transcription factor. Science 298:2385-2387.

Dobi A, Seabold GK, Christensen CH, Bock R, Alvarez VA (2011) Cocaineinduced plasticity in the nucleus accumbens is cell specific and develops without prolonged withdrawal. J Neurosci 31:1895-1904.

Duclot F, Kabbaj M (2017) The role of early growth response 1 (EGR1) in brain plasticity and neuropsychiatric disorders. Front Behav Neurosci 11:35.

Dudley CA, Erbel-Sieler C, Estill SJ, Reick M, Franken P, Pitts S, McKnight SL (2003) Altered patterns of sleep and behavioral adaptability in NPAS2deficient mice. Science 301:379-383.

Eipper-Mains JE, Kiraly DD, Duff MO, Horowitz MJ, McManus CJ, Eipper BA, Graveley BR, Mains RE (2013) Effects of cocaine and withdrawal on the mouse nucleus accumbens transcriptome. Genes Brain Behav 12:2133.

Enoch MA, Zhou Z, Kimura M, Mash DC, Yuan Q, Goldman D (2012) GABAergic gene expression in postmortem hippocampus from alcoholics and cocaine addicts; corresponding findings in alcohol-naive P and NP rats. PLoS One 7:e29369.

Falcon E, Ozburn A, Mukherjee S, Roybal K, McClung CA (2013) Differential regulation of the period genes in striatal regions following cocaine exposure. PLoS One 8:e66438.

Garcia JA, Zhang D, Estill SJ, Michnoff C, Rutter J, Reick M, Scott K, DiazArrastia R, McKnight SL (2000) Impaired cued and contextual memory in NPAS2-deficient mice. Science 288:2226-2230.

Gekakis N, Staknis D, Nguyen HB, Davis FC, Wilsbacher LD, King DP, Takahashi JS, Weitz CJ (1998) Role of the CLOCK protein in the mammalian circadian mechanism. Science 280:1564-1569.

Gelernter J, Sherva R, Koesterer R, Almasy L, Zhao H, Kranzler HR, Farrer L (2014) Genome-wide association study of cocaine dependence and related traits: FAM53B identified as a risk gene. Mol Psychiatry 19:717-723.

Graham DL, Edwards S, Bachtell RK, DiLeone RJ, Rios M, Self DW (2007) Dynamic BDNF activity in nucleus accumbens with cocaine use increases self-administration and relapse. Nat Neurosci 10:1029-1037.

Graziane NM, Sun S, Wright WJ, Jang D, Liu Z, Huang YH, Nestler EJ, Wang YT, Schlüter OM, Dong Y (2016) Opposing mechanisms mediate morphine- and cocaine-induced generation of silent synapses. Nat Neurosci 19:915-925

Groenewegen HJ, Wright CI, Beijer AV, Voorn P (1999) Convergence and segregation of ventral striatal inputs and outputs. Ann N Y Acad Sci 877: $49-63$.

Grueter BA, Robison AJ, Neve RL, Nestler EJ, Malenka RC (2013) FosB differentially modulates nucleus accumbens direct and indirect pathway function. Proc Natl Acad Sci U S A 110:1923-1928.

Heiman M, Schaefer A, Gong S, Peterson JD, Day M, Ramsey KE, SuárezFarinas M, Schwarz C, Stephan DA, Surmeier DJ, Greengard P, Heintz N (2008) A translational profiling approach for the molecular characterization of CNS cell types. Cell 135:738-748.

Henderson BW, Gentry EG, Rush T, Troncoso JC, Thambisetty M, Montine TJ, Herskowitz JH (2016) Rho-associated protein kinase 1 (ROCK1) is increased in Alzheimer's disease and ROCK1 depletion reduces amyloidbeta levels in brain. J Neurochem 138:525-531.

Hogenesch JB, Chan WK, Jackiw VH, Brown RC, Gu YZ, Pray-Grant M, Perdew GH, Bradfield CA (1997) Characterization of a subset of the basic-helix-loop-helix-PAS superfamily that interacts with components of the dioxin signaling pathway. J Biol Chem 272:8581-8593.

Imbesi M, Yildiz S, Dirim Arslan A, Sharma R, Manev H, Uz T (2009) Do- 
pamine receptor-mediated regulation of neuronal "clock" gene expression. Neuroscience 158:537-544.

Koike N, Yoo SH, Huang HC, Kumar V, Lee C, Kim TK, Takahashi JS (2012) Transcriptional architecture and chromatin landscape of the core circadian clock in mammals. Science 338:349-354.

Koo JW, Lobo MK, Chaudhury D, Labonté B, Friedman A, Heller E, Peña CJ, Han MH, Nestler EJ (2014) Loss of BDNF signaling in D1R-expressing NAc neurons enhances morphine reward by reducing GABA inhibition. Neuropsychopharmacology 39:2646-2653.

Kourrich S, Rothwell PE, Klug JR, Thomas MJ (2007) Cocaine experience controls bidirectional synaptic plasticity in the nucleus accumbens. J Neurosci 27:7921-7928.

Kupchik YM, Brown RM, Heinsbroek JA, Lobo MK, Schwartz DJ, Kalivas PW (2015) Coding the direct/indirect pathways by D1 and D2 receptors is not valid for accumbens projections. Nat Neurosci 18:1230-1232.

Landgraf D, Wang LL, Diemer T, Welsh DK (2016) NPAS2 compensates for loss of CLOCK in peripheral circadian oscillators. PLoS Genet 12:e1005882.

Levran O, Peles E, Randesi M, Correa da Rosa J, Ott J, Rotrosen J, Adelson M, Kreek MJ (2016) Glutamatergic and GABAergic susceptibility loci for heroin and cocaine addiction in subjects of African and European ancestry. Prog Neuropsychopharmacol Biol Psychiatry 64:118-123.

Lewitus GM, Konefal SC, Greenhalgh AD, Pribiag H, Augereau K, Stellwagen D (2016) Microglial TNF-alpha suppresses cocaine-induced plasticity and behavioral sensitization. Neuron 90:483-491.

Lobo MK, Nestler EJ (2011) The striatal balancing act in drug addiction: distinct roles of direct and indirect pathway medium spiny neurons. Front Neuroanat 5:41.

Lobo MK, Covington HE 3rd, Chaudhury D, Friedman AK, Sun H, DamezWerno D, Dietz DM, Zaman S, Koo JW, Kennedy PJ, Mouzon E, Mogri M, Neve RL, Deisseroth K, Han MH, Nestler EJ (2010) Cell type-specific loss of BDNF signaling mimics optogenetic control of cocaine reward. Science 330:385-390.

Lobo MK, Zaman S, Damez-Werno DM, Koo JW, Bagot RC, DiNieri JA, Nugent A, Finkel E, Chaudhury D, Chandra R, Riberio E, Rabkin J, Mouzon E, Cachope R, Cheer JF, Han MH, Dietz DM, Self DW, Hurd YL, Vialou V, et al. (2013) DeltaFosB induction in striatal medium spiny neuron subtypes in response to chronic pharmacological, emotional, and optogenetic stimuli. J Neurosci 33:18381-18395.

Logan RW, Williams WP 3rd, McClung CA (2014) Circadian rhythms and addiction: mechanistic insights and future directions. Behav Neurosci 128:387-412.

Logan RW, Hasler BP, Forbes EE, Franzen PL, Torregrossa MM, Huang YH, Buysse DJ, Clark DB, McClung CA (2018) Impact of sleep and circadian rhythms on addiction vulnerability in adolescents. Biol Psychiatry 83: 987-996.

Lu XY, Ghasemzadeh MB, Kalivas PW (1998) Expression of D1 receptor, D2 receptor, substance $P$ and enkephalin messenger RNAs in the neurons projecting from the nucleus accumbens. Neuroscience 82:767-780.

Lüscher C, Malenka RC (2011) Drug-evoked synaptic plasticity in addiction: from molecular changes to circuit remodeling. Neuron 69:650-663.

McCarthy MJ, Welsh DK (2012) Cellular circadian clocks in mood disorders. J Biol Rhythms 27:339-352.

McClung CA, Sidiropoulou K, Vitaterna M, Takahashi JS, White FJ, Cooper DC, Nestler EJ (2005) Regulation of dopaminergic transmission and cocaine reward by the clock gene. Proc Natl Acad Sci U S A 102:9377-9381.

Mead AN, Brown G, Le Merrer J, Stephens DN (2005) Effects of deletion of gria1 or gria2 genes encoding glutamatergic AMPA-receptor subunits on place preference conditioning in mice. Psychopharmacology 179:164171.

Miyazaki H, Oyama F, Wong HK, Kaneko K, Sakurai T, Tamaoka A, Nukina N (2007) BACE1 modulates filopodia-like protrusions induced by sodium channel beta4 subunit. Biochem Biophys Res Commun 361:43-48.

Moussawi K, Pacchioni A, Moran M, Olive MF, Gass JT, Lavin A, Kalivas PW (2009) $\mathrm{N}$-acetylcysteine reverses cocaine-induced metaplasticity. Nat Neurosci 12:182-189.

Mukherjee S, Coque L, Cao JL, Kumar J, Chakravarty S, Asaithamby A, Graham A, Gordon E, Enwright JF 3rd, DiLeone RJ, Birnbaum SG, Cooper DC, McClung CA (2010) Knockdown of clock in the ventral tegmental area through RNA interference results in a mixed state of mania and depression-like behavior. Biol Psychiatry 68:503-511.
Muñiz JA, Prieto JP, Gonzalez B, Sosa MH, Cadet JL, Scorza C, Urbano FJ, Bisagno V (2017) Cocaine and caffeine effects on the conditioned place preference test: concomitant changes on early genes within the mouse prefrontal cortex and nucleus accumbens. Front Behav Neurosci 11:200.

Nakagawa O, Fujisawa K, Ishizaki T, Saito Y, Nakao K, Narumiya S (1996) ROCK-I and ROCK-II, two isoforms of rho-associated coiled-coil forming protein serine/threonine kinase in mice. FEBS Lett 392:189-193.

Ozburn AR, Larson EB, Self DW, McClung CA (2012) Cocaine selfadministration behaviors in ClockDelta19 mice. Psychopharmacology 223:169-177.

Ozburn AR, Falcon E, Twaddle A, Nugent AL, Gillman AG, Spencer SM, Arey RN, Mukherjee S, Lyons-Weiler J, Self DW, McClung CA (2015) Direct regulation of diurnal Drd3 expression and cocaine reward by NPAS2. Biol Psychiatry 77:425-433.

Ozburn AR, Kern J, Parekh PK, Logan RW, Liu Z, Falcon E, Becker-Krail D, Purohit K, Edgar NM, Huang Y, McClung CA (2017) NPAS2 regulation of anxiety-like behavior and GABAA receptors. Front Mol Neurosci 10:360.

Parekh PK, Becker-Krail D, Sundaravelu P, Ishigaki S, Okado H, Sobue G, Huang Y, McClung CA (2018) Altered GluA1 (Gria1) function and accumbal synaptic plasticity in the ClockDelta19 model of bipolar mania. Biol Psychiatry 84:817-826.

Partch CL, Green CB, Takahashi JS (2014) Molecular architecture of the mammalian circadian clock. Trends Cell Biol 24:90-99.

Pierce RC, Bell K, Duffy P, Kalivas PW (1996) Repeated cocaine augments excitatory amino acid transmission in the nucleus accumbens only in rats having developed behavioral sensitization. J Neurosci 16:1550-1560.

Reick M, Garcia JA, Dudley C, McKnight SL (2001) NPAS2: an analog of clock operative in the mammalian forebrain. Science 293:506-509.

Russo SJ, Wilkinson MB, Mazei-Robison MS, Dietz DM, Maze I, Krishnan V, Renthal W, Graham A, Birnbaum SG, Green TA, Robison B, Lesselyong A, Perrotti LI, Bolaños CA, Kumar A, Clark MS, Neumaier JF, Neve RL, Bhakar AL, Barker PA, et al. (2009) Nuclear factor kappa B signaling regulates neuronal morphology and cocaine reward. J Neurosci 29: 3529-3537.

Russo SJ, Nestler EJ (2013) The brain reward circuitry in mood disorders. Nat Rev Neurosci 14:609-625.

Schmidt HD, Pierce RC (2010) Cocaine-induced neuroadaptations in glutamate transmission: potential therapeutic targets for craving and addiction. Ann N Y Acad Sci 1187:35-75.

Schoenbaum G, Stalnaker TA, Shaham Y (2007) A role for BDNF in cocaine reward and relapse. Nat Neurosci 10:935-936.

Shuen JA, Chen M, Gloss B, Calakos N (2008) Drdla-tdTomato BAC transgenic mice for simultaneous visualization of medium spiny neurons in the direct and indirect pathways of the basal ganglia. J Neurosci 28:26812685.

Shumay E, Fowler JS, Wang GJ, Logan J, Alia-Klein N, Goldstein RZ, Maloney T, Wong C, Volkow ND (2012) Repeat variation in the human PER2 gene as a new genetic marker associated with cocaine addiction and brain dopamine D2 receptor availability. Transl Psychiatry 2:e86.

Smith RJ, Lobo MK, Spencer S, Kalivas PW (2013) Cocaine-induced adaptations in D1 and D2 accumbens projection neurons (a dichotomy not necessarily synonymous with direct and indirect pathways). Curr Opin Neurobiol 23:546-552.

Spencer S, Torres-Altoro MI, Falcon E, Arey R, Marvin M, Goldberg M, Bibb JA, McClung CA (2012) A mutation in CLOCK leads to altered dopamine receptor function. J Neurochem 123:124-134.

Suto N, Tanabe LM, Austin JD, Creekmore E, Pham CT, Vezina P (2004) Previous exposure to psychostimulants enhances the reinstatement of cocaine seeking by nucleus accumbens AMPA. Neuropsychopharmacology 29:2149-2159.

Thiriet N, Aunis D, Zwiller J (2000) C-fos and egr-1 immediate-early gene induction by cocaine and cocaethylene in rat brain: a comparative study. Ann N Y Acad Sci 914:46-57.

Wu X, Wiater MF, Ritter S (2010) NPAS2 deletion impairs responses to restricted feeding but not to metabolic challenges. Physiol Behav 99: $466-471$.

Xu S, Kang UG (2014) Cocaine induces ubiquitination of egr-1 in the rat dorsal striatum. Neuroreport 25:1362-1367. 